\title{
Some Physical Properties of Polyaniline Blends Films
}

Received : 7/12/2017

Tariq J. Alwan, Abed Al-Khaliq S. Jabbar

Department of Physics, College of Education, Al Mustansiriyah University, Baghdad, Iraq

Email: tariqjaffer2000@yahoo.com

\begin{abstract}
$\underline{\text { Abstract: }}$
A polyaniline (Pani) blends films have been prepared successfully by the casting method. The Pani blends films of thickness $50 \mu \mathrm{m}$ have been prepared from the Pani and PMMA, PS and POE at constant concentration. The Pani blends films are characterized by X-ray diffraction and Fourier transform infrared spectroscopy, the presence of characteristic bonds of Pani blends films were observed from FTIR spectroscopy technique. Electrical properties revealed that conductivity of Pani blends films at room temperature are $5.18 \times 10^{-}$ ${ }^{9}, 9.23 \times 10^{-9}$ and $1.22 \times 10^{-8}{\mathrm{~S} . \mathrm{cm}^{-1}}$ for Pani blends with PMMA, PS and PEO, respectively. Mechanical properties show variation values of tensile stress and hardness for different Pani blends films.
\end{abstract}

Keywords :- Polyaniline, Blends, conducting polymer, PMMA, PS and POE.

\section{$\underline{\text { Introduction }}$}

A polymer blend is a mixture of two or more polymers that have been blended together to create a new material with different physical properties [1]. Polyaniline is an important intrinsically conducting polymers, due to its unique electrochemical properties and environmental stability [2]. Polyaniline exists in a variety of forms that differ in chemical and physical properties. The most common green protonated emeraldine has conductivity on a semiconductor level of the order of $100 \mathrm{~S} \mathrm{~cm}^{-1}$, many orders of magnitude higher than that of common polymers $\left(<10^{-9} \mathrm{~S} \mathrm{~cm}-1\right)$ but lower than that of typical metals $\left(>10^{4} \mathrm{~S} \mathrm{~cm}^{-1}\right)$. Protonated Pani, (e.g., P hydrochloride) converts to a nonconducting blue emeraldine base when treated with ammonium hydroxide [3]. The Pani have important features seem to be promising in vides area of practical applications in: rechargeable power sources), sensors, magnetic shielding, electrochemical capacitors, electrochromic devices, Solar cell, biosensors, corrosion protections, antistatic packaging materials, and light-emitting diode (LED) [4]. The Pani has been limited because of its poor, mechanical properties [5]. To improvement this properties will be blended with other conventional polymer. The PMMA, PS and POE are very famous conventional polymers, with great mechanical properties, and it has some common characteristics such as high transparent light and amorphous structure. The wide use of polymers in design applications involving bending and shock absorption requires emphasis on the mechanical properties [6]. Most blends have been created to improve combinations of mechanical characteristics [7].
In this paper, we blended the Pani with different types of polymers (PMMA, PS and POE ) at constant concentration and study electrical conductivity, structure and mechanical properties to find the best conventional polymer can be blend with Pani to fabrication Pani films.

\section{$\underline{\text { Details Experimental }}$}

Casting method used to prepare Pani blends films. To prepare Pani blends solution films, Pani.ES powder of weight $(0.05 \mathrm{~g})$ were dissolved in $5 \mathrm{ml}$ of chloroform to obtain a solution Pani. The mixture was placed in stirrer for $2 \mathrm{~h}$, in order to obtain homogenous solution, then add $0.2 \mathrm{~g}$ from PMMA to preparation Pani.PMMA solution, repeat the process with $0.2 \mathrm{~g}$ from PS to preparation Pani.PS solution and $0.07 \mathrm{~g}$ from PEO to preparation Pani.PEO solution, all polymeric solution with continuous stirring for $2 \mathrm{~h}$. Those solutions were poured into flat glass plate dishes and dried at room temperature for 4 days. SIDCO England series FTIR spectrometer is used to carry out the infrared analysis of the wave number that ranges 400 to 4000 $\mathrm{cm}^{-1}$. Structure characterization of the prepared samples are investigated by using Philips X-ray diffraction diffractometers.For Tensile test use tensile tester type (JIANQIAO TESTING EQUIPMENT), and for hardness test use hardness tester type Hardness (shore A) model TH200.

\section{$\underline{\text { Results And Discussion }}$}

Table 1. shows the variation of electrical conductivity of Pani films with different blends at 
room temperatures. The max conductivity is found for PAni.PEO blend and it was about $1.22 \times 10^{-8}$ S.cm ${ }^{-1}$, in general the high conductivity in PAni.PEO compare with other two blends may be attributed to the structure state of the films, it is important to note that obtained in this work are close to those found in the literature [8] . benzenoid ring), $1263 \mathrm{~cm}^{-1} \quad(\mathrm{C}-\mathrm{N} \quad$ stretching vibration), $1103 \mathrm{~cm}^{-1}$ (C-H in-plane defo rmation), $806 \mathrm{~cm}^{-1}$ (C-H out-of-plane deformation) selected to polyaniline. In addition, characteristic absorbtion band at $2968 \mathrm{~cm}^{-1}$ (methylene $\mathrm{C}-\mathrm{H}$ stretching) are asigned to polystyrene [10].

Table 1. The electrical and structure parameters of PAni blends

\begin{tabular}{|ccccc|}
\hline Samples & $\sigma$ S.cm $^{-1}$ & C.S A & Hardness & Tensile MPa \\
\hline Pani.PMMA & $5.18 \times 10^{-9}$ & 10.10 & 104 & 6.94 \\
\hline Pani.PS & $9.23 \times 10^{-9}$ & 11.34 & 102.8 & 5.88 \\
\hline Pani.PEO & $1.22 \times 10^{-8}$ & 10.20 & 105 & 2.338 \\
\hline
\end{tabular}

The three spectrums of examination of Xray diffraction in Figure 1. have peaks corresponding to PAni.PMMA, Pani.PS and Pani.PEO blends $[9,10,11]$, the X-ray spectrums with many peaks were assigned to polycrystalline structure for all films blends. From Figure 1. also see the Pani.PEO and PAni.PMMA blends have more peaks than Pani.PS blend, which mean the Pani.PS blend has low polycrystalline structure compare with other two blends. XRD analysis show a slight variation in crystalline size has been observed as shown in Table 1. which illustrates the variation in average grain size at blends, the average crystalline size is determined by using the Scherrer formula [12]:-

$$
\text { C.S. }=\frac{A \lambda}{\Delta \theta \cos \theta} \ldots \ldots . .1
$$

Where A Scherrer constant, commonly assume $\mathrm{A}=1, \Delta \theta$ is the full - width at half maximum of the XRD peak appearing at the diffraction angle $\theta$. It is be found the Pani.PS blend has max average grain size.

The FTIR spectra of PAni.PMMA, Pani.PS and Pani.PEO blends are shown in Figure 2, 3 and 4, that indicates to the details of functional groups present in these blends.

The FTIR spectra of PAni.PMMA film shows in the Figure 2. from this data it is clear that peaks is corresponding to PMMA which are observed in the blended polyaniline [9]. It is noticed appearance of a peak at $1730 \mathrm{~cm}^{-1}$ refer to $(\alpha, \beta$ unsaturated ) [13]. These alterations can be appointed to the construction of hydrogen bonding between these groups as a result of $\mathrm{H}$ donation in $\mathrm{NH}$ group. The H-bonding provide harmonization between polyaniline and carbonyl group in PMMA and develops the formation of an inter-penetrating network of polyaniline and the matrix chain [14].

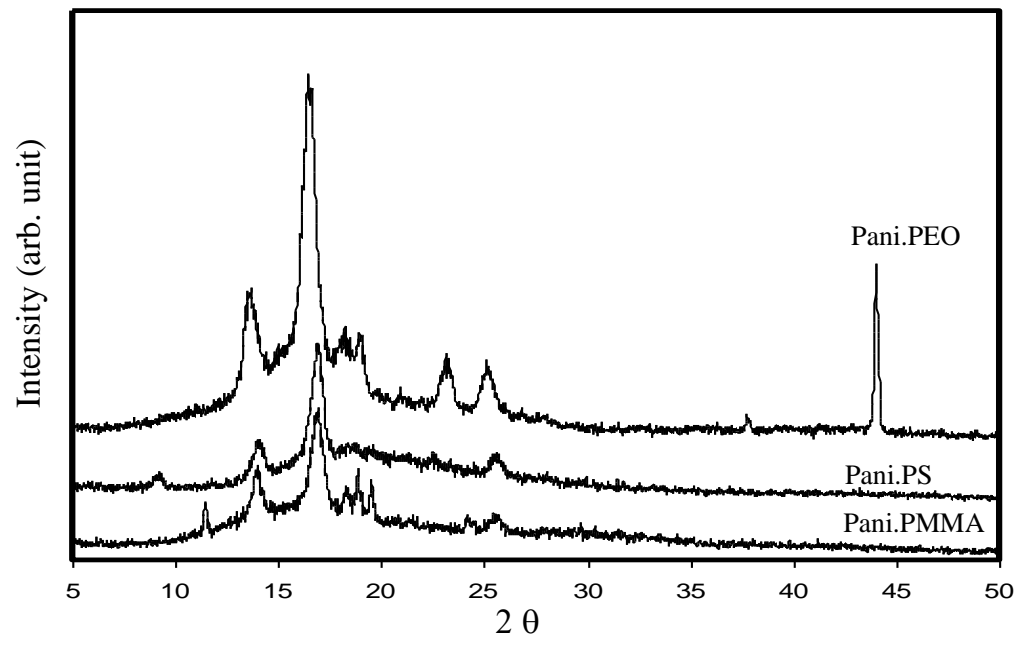

Figure 1. The XRD spectra of PAni blends

FTIR spectrum for PAni.PS blend show in Figure 3. as can be seen in figure the characteristic peaks of the PAni.PS blend were shown at $1740 \mathrm{~cm}^{-}$ ${ }^{1}(\mathrm{C}=\mathrm{C}$ stretching vibration of the quinoid ring), $1493 \mathrm{~cm}^{-1}$ (stretching vibration of $\mathrm{C}=\mathrm{C}$ of the
The FTIR spectra of PAni. PEO blend is shown in Figure 4. from this data it is clear that peaks corresponding to PEO are observed in the blended polyaniline. The appearance of peaks along 
with changes in existing directly indicates the blend formation, the spectras of PAni.PEO samples were seen as IR absorption peak at a wave number of $2893 \mathrm{~cm}^{-1}$, and these refer to presence of $\mathrm{OH}$ bonding because of hydrogen bonding in the $\mathrm{NH}$ stretch between PEO and PAni [11].

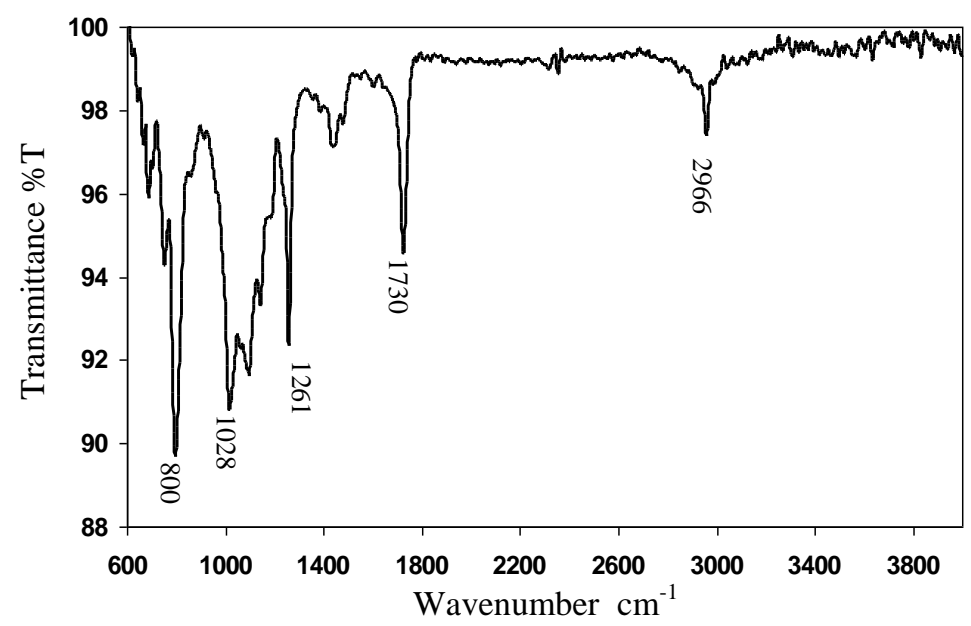

Figure 2. The FT-IR spectra of Pani.PMMA.

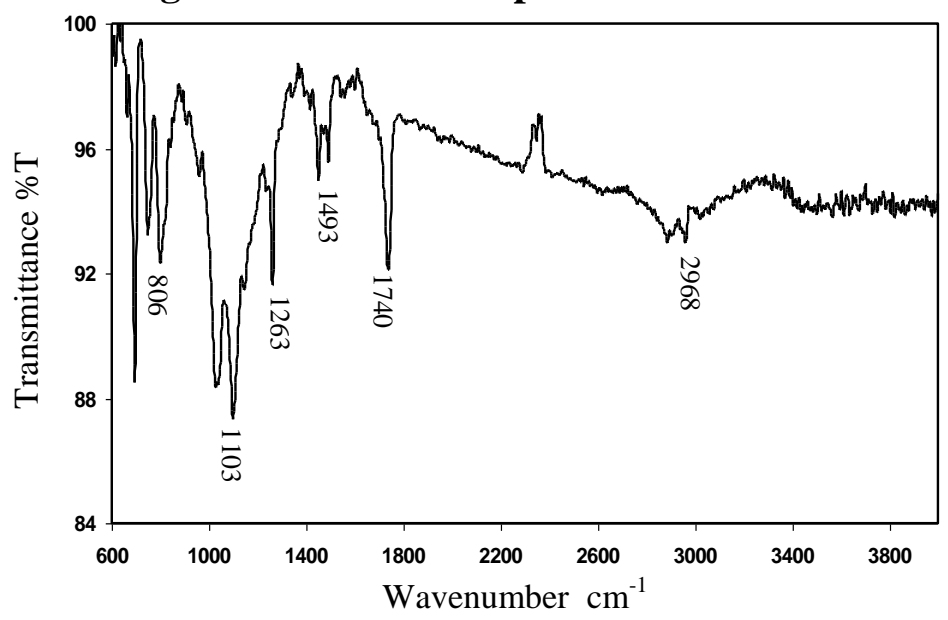

Figure 3. The FT-IR spectra of Pani.PS.

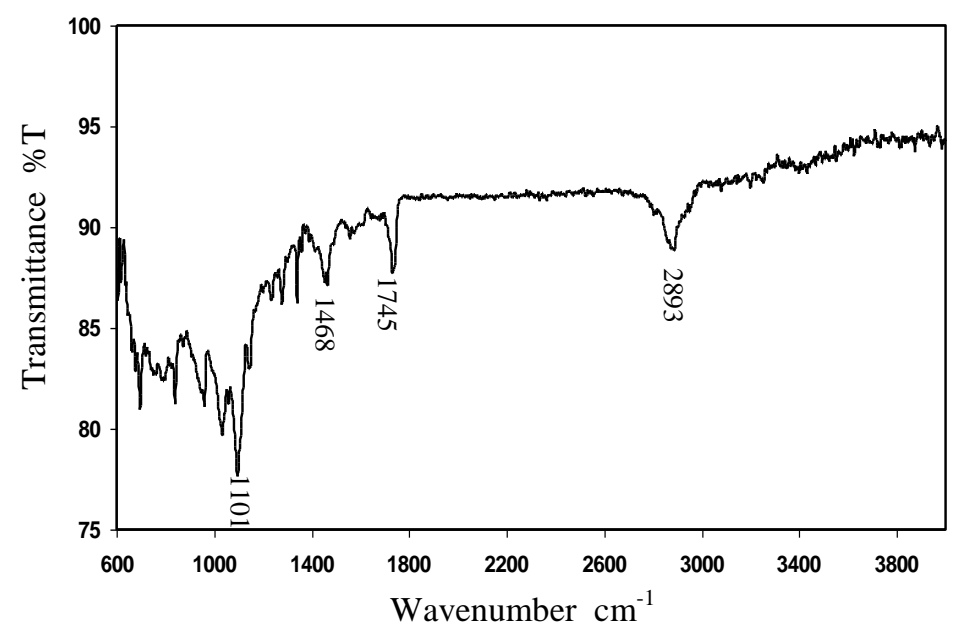

Figure 4. The FT-IR spectra of Pani.PEO. 
Hardness means the measure of materials resistance to localized plastic deformation. Hardness tests are performed more frequently than any other mechanical test for several reasons, it is simple and inexpensive, nondestructive, and other mechanical properties often may be estimated from hardness data, such as tensile strength.

Hardness testing is carried out to determine the hardness of the Pani blends and determine the effect of add (PMMA, PS and PEO polymer) on the results. The hardness values of PAni.PMMA, Pani.PS and Pani.PEO blends are listed in Table 1.

It can be seen that the Pani.PEO blend has the maxiumam value for hardness about 105 , and this is may be because the high-strength reinforcements between the Pani and PEO blend, thus increasing their hardness property. While the Pani.PEO blend has miumam value of tensile as see in Table 1. that show the values of tensile strength Pani blends and it can be not that the Pani.PMMA blend has the maxiumam value for tensile strength about 6.94 Mpa.

\section{Conclusions}

The Pani Blends films have been successfully prepared by casting method for different Pani blends (Pani.PMMA, Pani.PS and Pani.PEO), The systematic study was conducted for structure, mechanical and electrical conductivity. The XRD show the all sample have polycrystalline structure, and FT-IR spectra revealed the incorporation of Pani blands. From D.C conductivity we found the Pain.PEO has best conductivity, the Pani.PMMA has the maxiumam value for tensile strength. Thus we believe that Pain blends films could have potential applications, especially in flexible electronic devices.

\section{$\underline{\text { References }}$}

1. S. Thomas, Y. Grohens and P Jyotishkumar 2015, Characterization of Polymer Blends: Miscibility, Morphology, and Interfaces
(First Edition, Wiley-VCH Verlag GmbH \& Co. KGaA. Published).

2. Cheng-Ho Chen, 2002, Journal of Polymer Research. 9, p.195.

3. J. Stejskal, R. G. Gilbert, 2002, Pure Appl. Chem. 74, 5, p. 857

4. M. M. Gvozdenovic, B. Z. Jugovic, J. S. Stevanovic, T. Lj. Trisovic and B. N. Grgur, 2011, Electrochemical Polymerization of Aniline", Electropolymerization, (Editor by Dr. Ewa Schab-Balcerzak InTech)

5. J. Bhadra, N. J. Al-Thani, N. K. Madi, M. A. Al-Maadeed, 2015, Arabian Journal of Chemistry DOI: http://dx.doi.org/10.1016/j.arabjc.2015.04.01 7 In Press.

6. James F. Shackelford, 1998, Introduction to Materials Science for Engineers (SI edition. Prentice hall Europe)

7. William D. Callister Jr., 2000 Materials Science and Engineering. An Introduction (John Wiley and Sons Inc. U.S.A.)

8. José E. Pereira da Silva, Mrcia L. A. Temperini and Susana I. Crdoba de Torresi, 2005, J. Braz. Chem. Soc. 16, 3A, p 322.

9. Fatima Salh Jalli, 2017, Fabrication and Characterization of Nanofibers Polyaniline Blend Prepared by Electrospinning Method M.Sc., Thesis Al-Mustansiriya University College of Education Physics Department

10. Z. Taghipour, H. Eisazadeh, M. Tanzifi, 2014, IJE TRANSACTIONS B: Applications ,27, 2, p. 227.

11.Tariq J. Alwan, Kareema M. Ziadan, Kadhum J. Kadhum, 2013, International Review of PHYSICS (I.R.PHY), 7, 2, p.185.

12.B. D. Cullity, S. R. Stock, 2001, Elements of X-Ray Diffraction (3th edition PrenticeHall in the United States of America)

13. Sabe Thomas, Yves Grohens, Neethu Ninan, 2015, Nanotechnology Applications for Tissue Engineerin, (1st Edition, William Andrew)

14.Dhananjay D. Pise, B. B. Ahuja, S. M. Shendokar, 2015, International Journal of Science and Research (IJSR), 4, p.155 
